\title{
А.К. Сабитова
}

Карагандинский государственный университет имени академика Е. А. Букетова

\section{Гендерные исследования в}

\section{Центарльной Азии, Казахстанский кейс}

\begin{abstract}
Аннотация
В этой статье передается взгляды автора по состояниям гендерных исследований в Центральной Азии, особенно Казахстана. Размышляется о целях, результатах и эффектах проведенных исследований с периода независимотии страны. Одними из важных публичных исследований являются гендерные исследования как новая научная область и дисциплина высшего образования. Авторка приходит к выводу, что проект институциализации гендерных исследований не увенчался успехом в Центральной Азии
\end{abstract}

Ключевые слова: Центральная Азия, гендерные исследования, Казахстан 


\section{Gender Studies in Central Asia, Kazakhstan Case}

\section{Abstract}

This article conveys the views of the author on the status of gender studies in Central Asia, especially Kazakhstan. It reflects on the goals, results, and effects of the research conducted since the country's independence. One of the important public studies is gender studies as a new scientific field and the discipline of higher education. The author concludes that the project to institutionalize gender studies was not successful in Central Asia

Keywords: Central Asia, gender studies, Kazakhstan

\section{Введение}

Трудности проведения в жизнь гендерной политики в Казахстане, с которыми столкнулось сначала женское движение, а затем правительство, в частности Национальная комиссия по делам женщин и семейно-демографической политике при Президенте Республики Казахстан, объясняются целым комплексом причин институционального и личностного порядка. В данном тексте я рассмотрю часть этой проблемы - трудности институциализации гендерных исследований в Казахстане, внешние и внутренние причины неприживаемости этой области знания в локальном контексте. Начнем с того, что гендерная политика, гендерное образование и гендерные исследования на постсоветском пространстве возникли не самопроизвольно, не из внутренних потребностей общества и науки, а были импортированы с Запада как часть большого модернизационного политического проекта, предложенного нам и другим странам транзита и «третьего мира». Роль международных доноров в появлении, укреплении и спаде женского движения и гендерных исследований в нашем регионе ни для кого не является секретом, их воздействию на Казахстан посвящена одна из моих работ (Shakirova 2015).

Гендерные исследования на постсоциалистическом пространстве: борьба США и ЕС за влияние

В свое время меня поразила точка зрения немецко-австрийской исследовательницы Сюзан Циммерманн, профессорки Департамента гендерных 
исследований Центрально-Европейского университета в Будапеште. Ее статья (Zimmermann 2005) о становлении гендерных исследований в постсоциалистических странах как о целенаправленном западном проекте, осуществляемом при финансовом участии международных организаций и западных частных фондов, является, на мой взгляд, одной из самых проницательных на эту тему.

Скрупулезно проследив логику роста женских и гендерных исследований в регионе, исследовательница обнаружила, что первые центры гендерных исследований появились без влияния государственных и внешних политических акторов, к примеру, в Любляне (1986), Москве (1990), Бухаресте (1990), Лодзи (1992). Лишь в Праге (1991) такой центр возник при поддержке немецкого фонда ФрауэнАнштифтунг (см. Zimmermann 2005: 65-66). Во второй половине 1990-х на арене появляются американцы и создают, по словам Циммерманн, «теневую сеть высшего образования» (shadow network of higher education), имеющую англосаксонский характер. Ее главным форпостом стал Центрально-Европейский университет, открытый Джорджем Соросом в 1991 г. в Будапеште. Благодаря энергии Ненси Стэпан, супруги тогдашнего ректора ЦЕУ, в 1996 г. там открылась академическая программа по гендерным исследованиям как междисциплинарная программа с выдачей сертификата (Zimmermann 2005: 70). Последовали ряд семинаров по ГИ в самом ЦЕУ, недельные визиты в ЦЕУ преподавателей из постсоциалистического региона, летние школы и т.д. В основном появление гендерных исследований происходило в новых частных вузах, а параллельно с этим шло проникновение американских фондов в государственные вузы региона. Так, в 1992 г. фонд МакАртуров поддержал открытие «centers of excellence» в 25 госвузах России, годовой бюджет программы составил 7 млн долларов (Zimmermann 2005: $67)$.

Большую роль в становлении ГИ в регионе сыграли фонд Сороса, Институт Открытого общества и его Сетевая женская программа, которая поддерживала институциализацию гендерных исследований с 1997 г. При их поддержке в 1998 г. прошла первая конференция по женским и гендерным исследованиям в Белграде для 140 участниц из 30 стран, была издана директория женских и гендерных исследований этих стран. На постсоветском пространстве вторым центром после московского, который с 1994 г. начал работу по институционализации гендерных 
исследований, стал Харьковский ЦГИ. В 1997 г. при поддержке фонда МакАртуров был открыт ЦГИ при ЕГУ в Минске. При поддержке фонда Форда в 1997 г. в Европейском университете Санкт-Петербурга появляется магистерская программа по гендерным исследованиям. В Баку ЦГИ возник в 2000 г., в Бишкеке в Американском университете Центральной Азии - в 1993 г., хотя там и не было отдельного курса по гендерным исследованиям. В Алматы ЦГИ был инициирован Программой развития ООН и начал работу в 1998 г. Таким образом, полагает С. Циммерманн, теневая сеть престижных американских частных университетов установила гегемонию над дисциплиной гендерных исследований в регионе (Zimmermann 2005: 71).

Помимо становления гендерных исследований как университетской дисциплины правительства стран региона под влиянием новых международных стандартов стали нуждаться в гендерной экспертизе и статистике. Однако только этим невозможно объяснить, почему частные вузы, фонды и правительства оказались так заинтересованы в развитии женских и гендерных исследований в регионе. Глубинная коллизия состояла в асимметричной функциональности «гендера» как символа и инструмента политики транснациональных интересов в зоне конфликтных международных отношений. Международные акторы были заинтересованы в гендерных исследованиях не как в научной области, а как в способе распространения демократии и идеологии рыночной экономики. С середины 1990-х гг. связь гендерных исследований с дискурсом демократии становится неразрывной.

То, что гендер и гендерные исследования стали символами вестернизации, объясняется рядом факторов. Во-первых, полагает Циммерманн, права женщин всегда выступали методом политического доминирования Запада, еще со времен Британской империи, когда была озвучена проблема сати - ритуала сожжения вдов. Во-вторых, коммодификация женского труда и признание его важности для капиталистического производства стали поводом для признания гендерного равенства как одного из основных аспектов либеральной демократии. Кроме того, гендер как категория социального анализа, не находившая при социализме права на существование, пытается заместить или вытеснить собой понятие класса и классового анализа. Таким образом, во второй половине 1990-х гг. феминистски 
ориентированные исследователь_ницы и политические активист_ки, продвигавшие гендерные исследования, сами того не осознавая, оказались связанными с большой политикой - сферой высокой конкуренции за мировую гегемонию (Zimmermann 2005).

Анализируя ситуацию появления гендерных исследований на постсоциалистическом пространстве далее, Циммерманн указывает, что «с начала 2000-х пути развития гендерных исследований в трех регионах - Центральная и Восточная Европа, Россия и Центральная Азия - начали расходиться. В ЦВЕ шла EU-изация гендерных исследований, Болонский процесс. В России, Украине и Беларуси гендерная проблематика свелась к вопросам семьи, рынка труда и социальной политики, а в Центральной Азии и других неевропейских странах СНГ гендерные исследования поддерживаются донорами с целью “удержания в западной орбите"» (Zimmermann 2005: 78). Можно усмотреть в этой идее определенное упрощение и гомогенизацию анализируемого региона и целей западной финансовой помощи3 . Действительно, то, о чем писала Циммерманн, например, в отношении европейской части постсоветского пространства, более характерно для России, чем для Украины и Беларуси. Ее утверждение может быть поставлено под сомнение одним лишь перечислением тематики номеров журнала ХГЦИ «Гендерные исследования», а также многообразием тем и методологических подходов диссертаций, монографий, статей, конференций по гендерным исследованиям в России, Украине и Беларуси. Однако ее виденье процессов, происходящих с гендерными исследованиями в Центральной Азии, кажется мне достаточно убедительным.

В подтверждение тезиса Циммерманн об особой роли западного влияния для развития гендерных исследований в Центральной Азии можно привести большое число проектов и программ различных европейских и североамериканских доноров, реализованных при активной роли НПО. Например, в 1999 г. начала работу программа «Уполномоченное образование» с офисом в Киеве. Сетевая женская программа фонда Сороса очень успешно, на мой взгляд, провела трехлетнюю программу поддержки гендерных исследований в вузах, включавшую международную конференцию в Бухаре в 2003 г., летние школы на Иссык-Куле, а также издание серии книг «Гендерная коллекция - зарубежная классика», создание 
документальных фильмов из серии «Гендерный маршрут». В странах Центральной Азии бурному развитию гендерных исследований способствовали ежегодные конференции и летние школы. В 2001 г. алматинский ЦГИ провел первую студенческую научно-практическую конференцию «ГендерСтарт» в университете иностранных языков (КазУМОиМЯ им. Абылай хана) при поддержке американской информационной службы USIS (United States Information Service). Первая летняя школа по гендерным исследованиям для стран Центральной Азии проведена была авторкой данной статьи с коллегами в 2002 г. в Алматы (при поддержке HESP программы поддержки высшего образования Института открытого общества в Будапеште). В Кыргызстане прошла серия ежегодных летних школ по гендерным исследованиям. В 2005 г. при поддержке ЮНЕСКО был открыт центр гендерного образования в Казахском национальном университете имени аль-Фараби.

Другими словами, вывод, который предлагает Сюзан Циммерманн, таков: институциализация гендерных исследований может рассматриваться как часть большой геополитической игры, соревнования между США и Европейским союзом за влияние на постсоциалистический регион (Zimmermann 2005: 78). На мой взгляд, в настоящее время, в 2017 г., сущность этого противостояния воспринимается намного драматичнее, чем в 2005 г., поскольку после революции тюльпанов в Кыргызстане и других событий в Центральной Азии геополитическое значение нашего региона остается важным. В этой связи можно привести мнение российского исследователя Д. Попова о том, что «Центральная Азия если временно и выпадет из фокуса американской внешней политики, то в будущем будет неизбежно вновь и вновь в него возвращаться, а Вашингтон (хотя это официально и отрицается) будет играть здесь роль оппонента континентальным державам, аналогичную той, что ранее имела Британская империя» (Попов, 2016: 8). Поэтому высказываемая в этом тексте идея о включенности академической дисциплины «гендерные исследования» в более широкий геополитический аспект является, на мой взгляд, ключевой в понимании событий последней четверти века. К похожему заключению приходит и Елена Гапова в своем анализе развития гендерных исследований на постсоветском пространстве (Гапова 2010).

В то же время стоит отметить, что уже с середины 2000-х намечается спад интереса к финансированию гендерных проектов со стороны международных 
фондов. Например, в статье Елены Кочкиной «Гендерные исследования в России: от

фрагментов к критическому переосмыслению политических стратегий» приводятся данные, согласно которым «Объем финансирования западными донорами гендерных проектов сократился в 2006 г. по сравнению с 2003 г. раз в 10» (Кочкина 2007: 113). Таким образом, процесс развития гендерных исследований и его связь с западной финансовой помощью являются более сложными, чем они представлены в тексте Циммерманн, особенно если читать его с перспективы сегодняшнего дня.

\section{Гендерные исследования в Центральной Азии}

Тема становления гендерных исследований в неевропейских республиках СНГ стала объектом внимания не только европейских ученых, но и ряда исследователь_ниц из России (Анна Темкина, Елена Здравомыслова, Ирина Тартаковская, Сергей Абашин), а также русскоязычных исследователь_ниц, аффилированных в западных университетах (например, Мадина Тлостанова, Сергей Ушакин).

Вскоре о становлении гендерных исследований и женского движения в бывших республиках СССР писали известные российские исследовательницы Елена Здравомыслова и Анна Темкина. За 20 лет развития мы получили те же итоги, что феминизм на Западе за 40 лет- «маргинализация, геттоизация, поколенческие разрывы, демобилизация в женском движении, размывание политического субъекта в постмодернистской парадигме» (Здравомыслова, Темкина 2007: 76). Однако авторки не склонны к драматизации ситуации и демонизации международных акторов, что характерно для Сюзан Циммерманн. Ими принимается во внимание политический контекст (путинская Россия и ее отношения с ЕС и США), они считают, что феминисток и гендерных исследователь_ниц разных стран сближает критическая позиция. В целом все, на что Циммерман смотрит подозрительно, у российских авторок вызывает позитивные чувства (летние школы, виртуальные сети, информационные рассылки, печатные и онлайн-издания, новые курсы).

Таким образом, настойчиво повторяется проблема восприятия гендерных исследований как части западной культуры, западной академической и политической идеологии, что особенно активно в последнее время стало конструироваться как конфликт с тем, что мыслится как «местное», «локальное», 
«традиционное». Как привнесенное извне знание гендерные исследования всегда нуждались в поддержке - и финансовой, и моральной. Финансирование гендерного образования в Казахстане, особенно вузовского, никогда не было приоритетной задачей международных организаций, за исключением ПРООН. Для большинства доноров гендерные исследования относились к академической области, не влиявшей напрямую на эффективность внедряемых программ развития в силу ограниченности целевой группы. Однако все доноры признавали нехватку профессиональных экспертов в области гендерных отношений, особенно со знанием английского языка. Что касается финансирования образовательных и исследовательских проектов, можно уверенно констатировать, что наиболее благоприятные годы для их развития пришлись на конец 1990-х - начало 2000-х гг. (конкретные примеры представлены в предыдущем разделе).

Для продвижения новой дисциплины важно учитывать языковой ландшафт той или иной страны. В Казахстане, в отличие от России, стояла задача развития гендерных исследований на собственной национальной основе, на своем государственном языке. Эту особенность вовремя осознали украинские гендерные исследователь_ницы, одним из примеров этого стал перевод «Второго пола» Симоны де Бовуар, изданный в Украине раньше, чем в России. Иная ситуация сложилась в Казахстане. Все защиты диссертаций по гендерной тематике у нас проходили на русском языке, монографии и статьи публикуются на русском языке, учебной литературы на казахском языке очень мало. Это было связано как с отсутствием социального заказа на издание такой литературы, так и с недостатком переводческого потенциала ученых, привыкших работать на русском языке. Но у этой задачи есть и другой ракурс. В последнее время стало принято настаивать на преимуществе национального способа организации гендерных отношений в интересах возрождения традиций, определения национальной и культурной идентичности казахского народа. На протяжении 25 лет независимости идут процессы построения новой нации, выработки как общегражданской идеи единства народов страны (Казахстан - наш общий дом), так и этнически маркированной идеи священной земли казахов («Мәңгілік ел»). Следовательно, гендерные исследования должны отвечать и на теоретические вопросы нациостроительства. Какие образы предлагаются казах(стан) скому народу в качестве национальных героев и героинь?

\section{Year 3 (2018) Vol:3, Issue: 1 www.worldwomenstudies.com 
Не слишком ли мифологизируется золотой век казахской истории в аспекте его гендерно-ролевых образцов? Не является ли поэтизация батыров, ханов и цариц попыткой закрепить вторичные, обслуживающие, незаметные роли обычных женщин в обществе? Вклад гендерных исследователей в критическое осмысление работ национал-патриотической интеллигенции, на мой взгляд, был бы сегодня как никогда своевременным.

\section{О деколониальности в ГИ}

Кроме этого, в наших географических и геополитических реалиях невозможно не поставить вопрос о гендерных исследованиях и феминизме с позиций деколониального поворота. В социально-гуманитарную сферу постсоветских стран благодаря московской исследовательнице Мадине Тлостановой была введена концепция деколониальности. В ее книге «Деколониальные гендерные эпистемологии» (Тлостанова 2009) впервые в русскоязычной научной литературе поставлен вопрос об уникальности феминистского голоса стран Закавказья и Центральной Азии, проведена параллель феминизма нашего региона с феминизмами стран третьего мира - Мексики, Египта, Китая, Нигерии, ЮАР, стран Карибского бассейна (подробнее о книге см.: Абашин, Шакирова 2010).

Тлостанова полагает, что развитие женского движения на постсоветском пространстве явилось частью более глобального политического проекта, в котором на новом витке воспроизводится противостояние и логика взаимодействия бывшего первого, второго и третьего миров- в терминах деколониального проекта, «колониальности власти» и «колониальности гендера». Авторка задает вопрос: возможно ли внутри этого противостояния практиковать некую степень независимости и альтернативного выбора для центральноазиатского гендерного активизма? Наряду с комплиментами в адрес исследовательниц Казахстана и Узбекистана, производящих аутентичный гендерный дискурс своего региона, высказываются и критические оценки, относящиеся, в частности, к тому, что, как правило, все социальные, политические и экономические проблемы у нас интерпретируются в рамках дискриминации женщин вообще мужчинами вообще (Тлостанова 2009: 359-360). 
Логично задать вопрос: а что сегодня происходит у нас с гендерными исследованиями? Поддерживает ли их еще кто-нибудь? Рыночная идеология 23 утвердилась, геополитические игроки заняли свои позиции в регионе, ценности демократии никого уже, как прежде, не впечатляют, хотя и собирают под свои знамена верных правозащитников. Министерству образования и науки Республики Казахстан гендерные исследования не были нужны раньше и не нужны по сей день. Феминизм, хотя и вошел в повседневный оборот, по-прежнему ассоциируется с его радикальной ветвью, которая в последние годы помолодела и носит открытый ЛБГТ-характер. В университетах гендерные курсы как проявление «непристойного дополнения» чахло доживают свое. Если они и существуют сегодня, так только в таких американских институциях, как Казахстанский институт менеджмента, экономики и прогнозирования (КИМЭП), Назарбаев Университет и др. С чего начали, тем и завершили. 


\section{Литература}

Kotkin S. 2006. Report on Western Support for Higher Education in the Russian Federation.

Елена Гапова. 2011. Национальное знание и международное признание: постсоветская академия в борьбе за символические рынки // Ab Imperio. № 4. С. 289323.

Shakirova S. 2015. Gender Equality Policy in Kazakhstan and the Role of International Actors in its Institutionalization. In: Institutionalizing Gender Equality Historical and Global Perspectives. Ed. by Yulia Gradskova and Sara Sanders. L: Lexington Books. P. 209-224.

Shakirova S. 2013. Gender Policy and Nation-Building in Kazakhstan: Parallel or Opposing Processes? In: Gender \& Human Development in Central and South Asia. Ed. by Mondira Dutta. New Delhi, India, Pentagon Press. P. 253-262.

Zimmermann S. 2005. Frauen und Geschlechterstudien in hoeheren Bildungswegen in Zentraleuropa und im postsowjetischen Raum / The Institutionalization of Women and Gender Studies in Higher Education in Central and Eastern Europe and the Former Soviet Union: Asymmetric Politics and the Regional-Transnational Configuration. L'Homme: Europäische Zeitschrift für feministische Geschichtswissenschaft. № 16. S. 63-88.

Абашин С., Шакирова С. 2010. «Деколониальные гендерные эпистемологии» Мадины Тлостановой: новые академические вызовы гендерным исследованиям в России? // Гендерные исследования. № 19. С. 267-279. Электронный ресурс: http://www.gender.univer.kharkov.ua/gurnal/19/18.pdf

Гапова Е. 2010. Гендерные исследования как зеркало постсоветской академии. В: Антропология академической жизни: междисциплинарные исследования. Т. II. Отв. ред. и составитель Г.А. Комарова. М.: ИЭА РАН.

Жеребкина И. 2003. Гендерные 90-е, или Фаллоса не существует. СПб.: Алетейя. 
Здравомыслова Е., Темкина, А. 2007. Автономизация гендерных исследований в транснациональном пространстве: феминистские практики // Гендерные исследования. № 15. С.75-91.

Зубковская О. 2007. Постколониальная теория в анализе постсоветского феминизма: дилеммы применения //Ab Imperio. № 1. С. 395-420.

Кочкина Е. 2007. Систематизированные наброски. Гендерные исследования в России: от фрагментов к критическому переосмыслению политических стратегий // Гендерные исследования. № 15. С. 92-143.

Попов Д.С. 2016. Центральная Азия во внешней политике США: 1991-2016 годы. М.: РИСИ.

Тартаковская И., Попкова Л. 2008. Gender Studies Curriculum Development (Cases of Kazakhstan and Kyrgyzstan).

Тлостанова М. 2009. Деколониальные гендерные эпистемологии. М.: ООО «ИПЦ "Маска"»,

Шакирова С. 2010. Гендерные символы национальной идеи: современные дискуссии в Казахстане // Гендерные исследования. № 19. С. 186-202.

Шакирова С. 2005. Обзор гендерного образования в Казахстане // Гендерные исследования, гендерная политика и женское движение в странах Центральной Азии: попытка диагноза. Алматы: Фонд им. Ф. Эберта, Центр гендерных исследований, Центр гендерного образования КазНУ им. аль-Фараби, С. 96-130. 